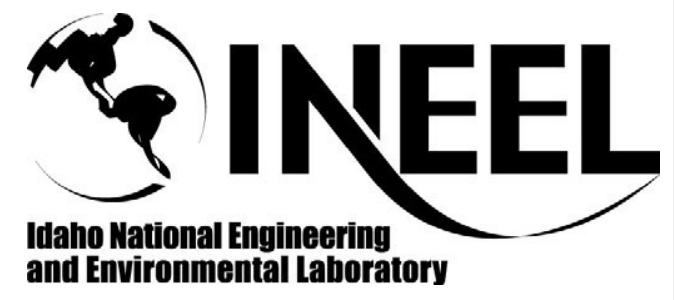

\author{
INEEL/CON-05-02604 \\ PREPRINT
}

Correlations Of Nucleate Boiling Heat Transfer And Critical Heat Flux For External Reactor Vessel Cooling

\author{
J. Yang \\ F. B. Cheung \\ J. L. Rempe \\ K. Y. Suh \\ S. B. Kim
}

July $17-22,2005$

2005 ASME Summer Heat Transfer Conference

This is a preprint of a paper intended for publication in a journal or proceedings. Since changes may be made before publication, this preprint should not be cited or reproduced without permission of the author. This document was prepared as an account of work sponsored by an agency of the United States Government. Neither the United States Government nor any agency thereof, or any of their employees, makes any warranty, expressed or implied, or assumes any legal liability or responsibility for any third party's use, or the results of such use, of any information, apparatus, product or process disclosed in this report, or represents that its use by such third party would not infringe privately owned rights. The views expressed in this paper are not necessarily those of the U.S. Government or the sponsoring agency. 


\section{CORRELATIONS OF NUCLEATE BOILING HEAT TRANSFER AND CRITICAL HEAT FLUX FOR EXTERNAL REACTOR VESSEL COOLING}

\author{
J. Yang and F. B. Cheung \\ Department of Mechanical \& Nuclear Engineering \\ Pennsylvania State University \\ University Park, PA 16802, USA \\ fxc4@psu.edu \\ K. Y. Suh \\ Department of Nuclear Engineering \\ Seoul National University \\ Seoul, Korea
}

\author{
J. L. Rempe \\ Idaho National Engineering and \\ Environmental Laboratory \\ P.O. Box 1625, Idaho Falls, ID \\ S. B. Kim \\ Korea Atomic Energy Research Institute \\ P.O. Box 105, Yuseoung \\ Taejon, Korea
}

\begin{abstract}
Four types of steady-state boiling experiments were conducted to investigate the efficacy of two distinctly different heat transfer enhancement methods for external reactor vessel cooling under severe accident conditions. One method involved the use of a thin vessel coating and the other involved the use of an enhanced insulation structure. By comparing the results obtained in the four types of experiments, the separate and integral effect of vessel coating and insulation structure were determined. Correlation equations were obtained for the nucleate boiling heat transfer and the critical heat flux. It was found that both enhancement methods were quite effective. Depending on the angular location, the local critical heat flux could be enhanced by 1.4 to 2.5 times using vessel coating alone whereas it could be enhanced by 1.8 to 3.0 times using an enhanced insulation structure alone. When both vessel coating and insulation structure were used simultaneously, the integral effect on the enhancement was found much less than the product of the two separate effects, indicating possible competing mechanisms (i.e., interference) between the two enhancement methods.
\end{abstract}

\section{INTRODUCTION}

The concept of external passive cooling of core melt in the lower head of a reactor vessel by cavity flooding has been adopted by some operating nuclear power plants and proposed for some advanced nuclear reactor designs as a viable strategy for severe accident management. In this concept, water is made available on the bottom side of the reactor vessel by flooding the reactor cavity during a severe core-meltdown accident. The decay heat generated in the melt material is then removed from the external bottom surface of the reactor vessel by boiling of the water in the flooded cavity. As long as the boiling remains within the nucleate boiling regime in the post-accident stage, which requires the local wall heat flux to be below the critical heat flux (CHF), thermal failure of the reactor vessel can be prevented and the radioactive core melt can be retained within the reactor vessel. However, upgrading of the reactor power capacity results in higher thermal loads following a coremeltdown accident which call for methods to enhance decay heat removal.

Two distinct boiling heat transfer enhancement methods have been proposed by Cheung et al. (2003) for external reactor vessel cooling (ERVC). One method involves surface modification by applying an appropriate coating material on the vessel outer surface to promote downward facing boiling. Dizon et al (2004) proposed a viable type of metallic micro-porous layer surface coatings for ERVC. This type of coatings has been shown experimentally to be an effective passive enhancement technique capable of providing an increase in both the local nucleate boiling heat flux and local CHF compared to the performance of a plain surface (Liter and kaviany, 2001). O'Connor and You (1995) found a $109 \%$ increase in the CHF limit over a non-painted surface in saturated FC-72 with almost $80 \%$ reduction in nucleate boiling superheat. Chang and You (1996) obtained approximately $80 \%$ reduction in incipient superheat, $330 \%$ enhancement in nucleate boiling heat transfer, and $100 \%$ enhancement in CHF using micro-porous layer 
coatings made of copper particles $(1-50 \mu \mathrm{m})$ and aluminum particles $(1-20 \mu \mathrm{m})$. Dizon et al. (2004) obtained up to more than $100 \%$ increase in the $\mathrm{CHF}$ value at different angular locations of a downward facing curved surface under transient quenching conditions. Liter and Kaviany (2001) reported nearly three times enhancement of CHF using modulated porous-layer coatings. The observed enhancement with porous coatings is attributed to several effects: capillary pumping action on the liquid supply flow, increased number of nucleation sites, extended heat transfer surface area and the availability of the vapor escape paths from the porous coating to the liquid pool (Yang and Cheung, 2004). However, all these improvements offered by porous coating are mainly within the local scale, i.e., on the heating surface.

To further enhance ERVC globally, a second method has been proposed by Cheung et al. (2003). For many nuclear power plants, the reactor pressure vessel (RPV) is surrounded by a thermal insulation structure that forms a hemispherical annular flow channel with the vessel. As boiling of water takes place on the vessel outer surface, the vapor masses generated on the surface would flow upward through the annular channel under the influence of gravity. Because of the vapor motions, liquid water would be entrained in the flow, thus resulting in a buoyancy-driven upward co-current two-phase flow in the channel. A global enhancement to decay heat removal rate can be achieved by making modifications to the thermal insulation structure so that it would facilitate steam venting through the annular channel between the reactor pressure vessel and the surrounding insulation structure. Cheung et al. studied the downward facing boiling and critical heat flux phenomena on the outer surface of a hemispherical vessel through a threedimensional simulation of the boiling process with and without a surrounding insulation under various boiling and flow configurations in the subscale boundary layer boiling (SBLB) facility $(1997,1998,2003)$. They investigated the effect of different geometries and flow areas distribution of the thermal insulation structures on the upward two-phase flow motion and found that it had a positive impact on the local nucleate boiling rate and CHF limit.

In this study, four different ERVC cases were considered, including a plain vessel without thermal insulation structure (baseline case for comparison); a coated vessel without thermal insulation structure; a plain vessel with enhanced thermal insulation structure, and a coated vessel with enhanced thermal insulation structure. All four cases were experimentally explored in the SBLB facility. The two-phase flow behavior was observed under steady-state boiling conditions for each case. Moreover, nucleate boiling and CHF data were obtained from which correlations were developed. Based on the experimental results, CHF enhancement factors were determined showing the separate and integral effects of the two ERVC enhancement methods on the CHF limit.

It should be noted that there are no available nucleate boiling and CHF correlations in the literature that are applicable to the cases investigated in this study. Most reported data for porous layer coatings are for upward facing surfaces. The correlations presented in this study, which were obtained specifically for downward facing curved surfaces, provide the much needed information for the assessment of ERVC under severe accident conditions.

\section{EXPERIMENTAL METHOD}

\section{Metallic Micro-porous Surface Coating}

Metallic micro-porous surface coatings are coatings with extra-thin layer thicknesses that are less than the superheated layer thickness needed for activation of the cavities during nucleation (Czikk et al. 1981; Chang and You, 1997). The interconnected pores that are formed between the metallic particle packs create regions of low resistance to vapor escape and high capillary-assisted liquid draw. This would result in improved liquid-vapor counter-flow paths within the coating layer facilitating nucleate boiling heat transfer from the surface to the liquid pool.

Figure 1 shows the micrographs of sample aluminum and copper micro-porous coatings. The coatings were made from fine aluminum and copper particles wrapped in bonding material. The mixture of micro-porous coating comprised metallic particles, epoxy, and solvent. In this study, OB-200 epoxy consisting of a black-colored resin and a white-colored catalyst was used. OB-200 was identified as a suitable epoxy for the coating since it possesses several desirable qualities such as increased thermal conductivity, better tensile strength, and higher operating temperatures (up to $260^{\circ} \mathrm{C}$ ). For solvent, MEK was used because it is a high strength solvent with a low volatility.

An extensive characterization study of the coatings has been performed by Dizon et al. (2004). Different compositions of the coating material were evaluated in order to obtain a mixture with desirable qualities. Different painting techniques, including drip, brush, and spray painting, were explored. Durability and adhesion tests were then done to study the performance of each of the resulting coatings. Dizon et al., found that aluminum micro-porous layer surface coating was most suitable for use in ERVC, as it appeared very durable with little aging effects throughout a series of durability tests including abrasion, scratch, adhesion and boiling. Based on the spray coating method developed by Dizon et al. (2004), test vessels were coated with aluminum micro-porous layer coating for use in the present study.

\section{Enhanced Insulation Structure}

Figure 2 shows the enhanced thermal insulation design employed in this study with indication of the annular flow channel that is formed between the insulation and the reactor vessel. The design simulates the configuration of the Korean Advanced Power Reactor APR1400, which is the reactor under consideration in this study. Note that there is a bottleneck between the reactor vessel and the insulation structure in the minimum gap location near the shear key position. The present insulation structure has the enhanced design features proposed by Cheung et al. (2003), which uses a non-uniform gap size for 
enlarging the bottleneck by opening the space available for steam venting in the circumferential locations away from the shear key positions. According to Cheung et al. (2003), by enlarging the minimum gap the pressure drop through the bottleneck could be reduced appreciably. As a result, more flow could be induced when subjected to the same downward facing boiling conditions, which in turn leads to a higher CHF limit.

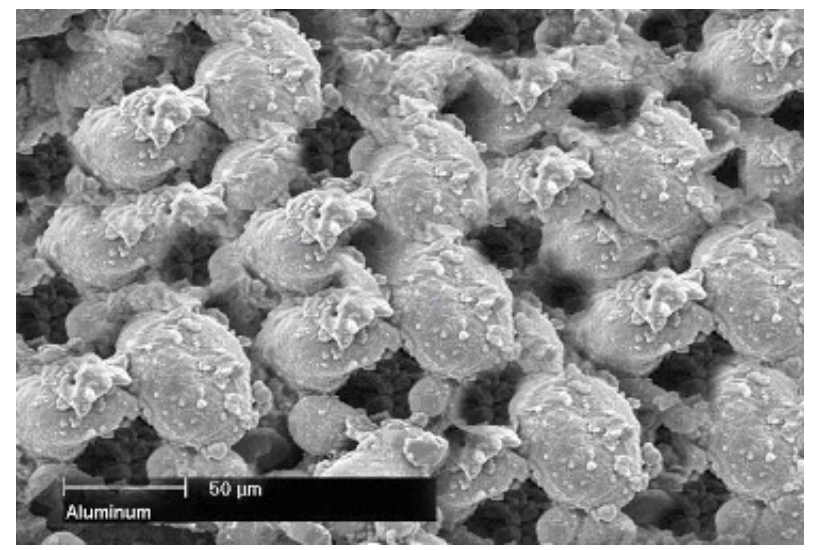

Aluminum Coating

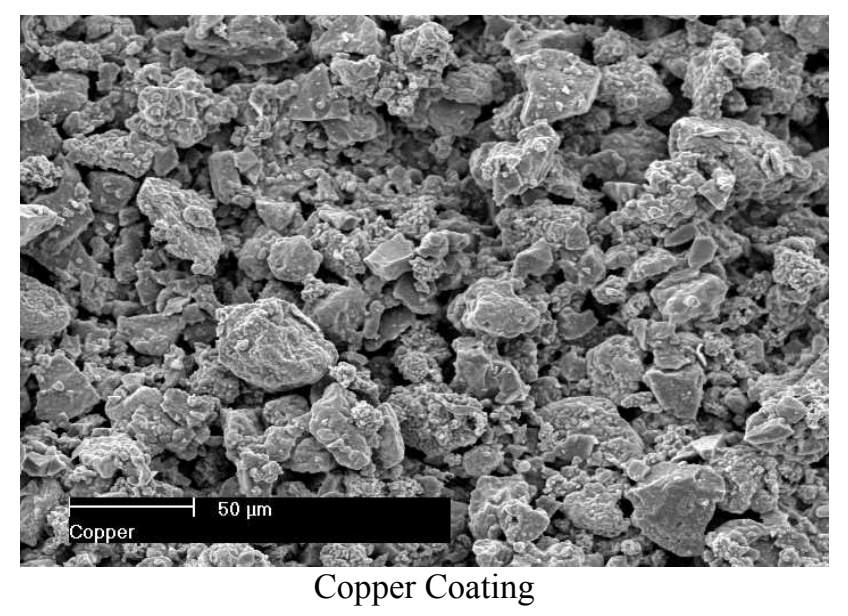

\section{Figure 1. SEM PHOTOS OF ALUMINUM AND COPPER MICRO-POROUS LAYER COATINGS}

\section{Subscale Boundary Layer Boiling (SBLB) Test Facility}

The test facility (see Fig. 3.) employed in this study consisted of a water tank with a condenser assembly, a heated hemispherical test vessel surrounded by a scaled insulation structure, a data acquisition system, a photographic system, and a power control system. The test vessel, having a diameter of $0.305 \mathrm{~m}$, had an interchangeable lower head simulator. Both a plain vessel and a coated vessel were used in this study. The water tank was designed to conduct boiling experiments under simulated ERVC conditions. The size of the water tank was chosen to accommodate hemispherical vessels of diameters up to $0.381 \mathrm{~m}$ and to minimize the effect of recirculation motions created by the boiling process. The tank contained large viewing windows for observation, video-taping and photo records, and was equipped with three immersion heaters with a total power of $36 \mathrm{~kW}$ for preheating the water to a desired temperature. The test vessel comprised two main parts: a heated hemispherical lower head simulator and a non-heated cylindrical upper portion. Groups of cartridge heaters were used to deliver power input to the lower head.

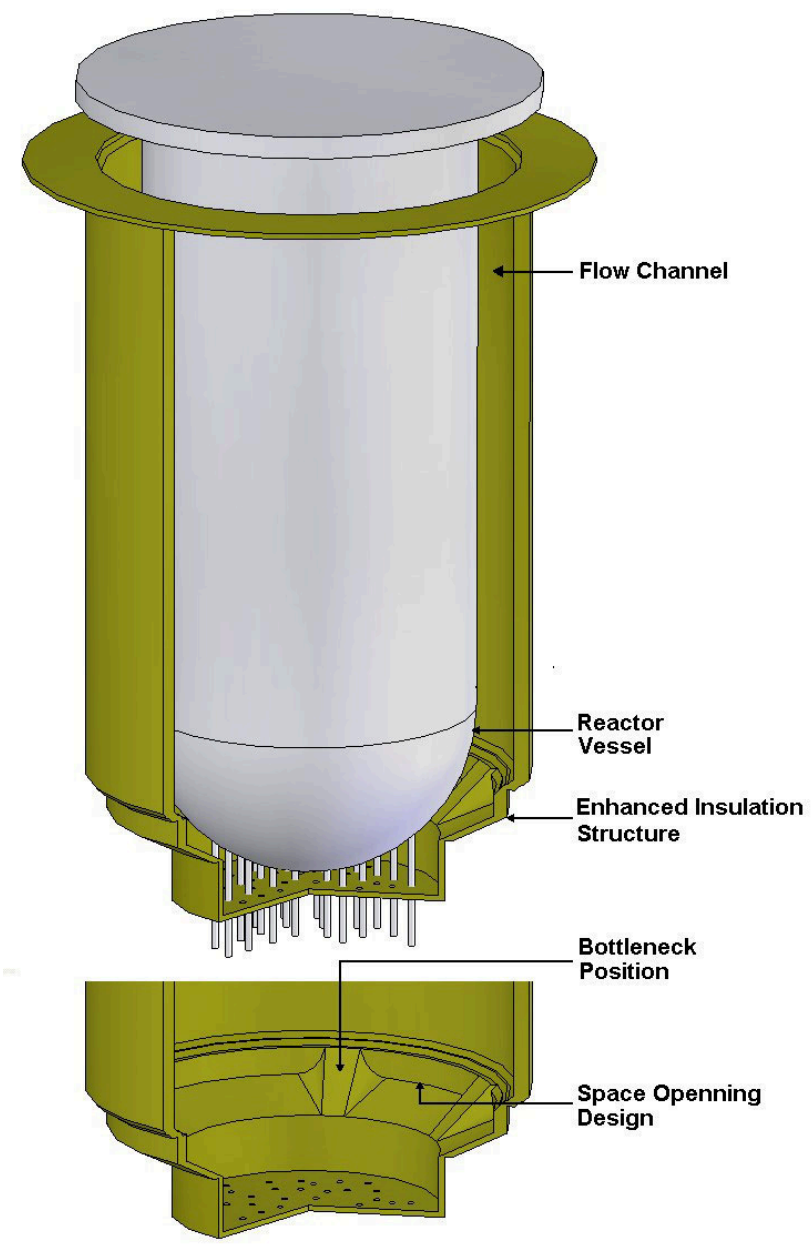

Figure 2. SCHEMATIC DIAGRAM OF THE REACTOR VESSEL ENHANCED INSULATION STRUCTUR

The data acquisition system, capable of monitoring 32 thermocouple signals with a sampling rate of up to twenty per second, was specifically calibrated for use in boiling experiments. An ACPC-16 board was installed in a computer. The ACPC-16 board had 16 analog inputs and 16 digital input/output channels. An additional ACPC-16 board could also be installed in the PC to give a total of 32 analog inputs. The ACPC-16 board had resolution capacities in the range of 12 to 16 bits, equivalent to $0.024 \%$ and $0.0015 \%$ of full scale, respectively. The board had six voltage ranges that could be set according to the sensor used. 


\section{Steady State Boiling Test Procedure}

Figure 4 shows the steady state boiling experimental procedure employed in this study. Before a run, the tank was first filled with water to the desired level. A pump was then used to circulate the water through a high-performance filter. This helped prevent water from becoming feculent during the heating process and also remove the particles within the water that would precipitate later. Then the immersion heaters were turned on to heat the water to a prescribed temperature. If the temperature fell below the desired value during an experiment, one of the heaters was turned on again to bring the water temperature back up. Before power was supplied to the groups of cartridge heaters inside the test vessel, the water was given time to become completely quiescent to minimize the circulatory motion caused by immersion heaters. In these tests, the water in the tank was maintained at the saturation temperature. The power supply cables and the thermocouple wires were then connected to the adjustable power suppliers and the data acquisition system, respectively. Each power supply circuit for a group of cartridge heaters was equipped with a multimeter that allowed the voltage across and current through the adjustable power suppliers to be measured. Next, the power sources to the adjustable power suppliers were turned on and the variac and/or SCR were set to deliver the desired heat flux level. At the same time, the temperatures at various locations inside the vessel wall were monitored on the computer screen using the data acquisition program Quicklog. Once steady state conditions were reached, the program Quicklog was used to record the steady state temperatures at various locations of the vessel wall and store them into a file for analysis.
Whenever it was decided to video tape the boiling process, a high speed video camera system was turned on after the desired steady state conditions had been reached. Then, the lighting was adjusted until a satisfactory image of the flow was obtained. The boiling process was also photographed directly using a digital camera and was then stored on the computer. Four types of steady state boiling tests with and without the enhanced thermal insulation structure were conducted, using plain test vessels and using coated vessels. By comparing the results obtained in these four types of tests, the separate and integral effects of vessel coating and the enhanced insulation structure could be determined.

\section{Types of Experiments}

Four types of steady state boiling experiments were performed in this study. The configuration of each type is described below:

1. Plain Vessel Without Surface Coating or Thermal Insulation: For this type of boiling tests, the outer surface of the vessel wall was first polished and cleaned for a smooth surface finish and normal cavity-size distribution because surface finish can shift the position of boiling curves noticeably. Steady state boiling tests were then performed without installation of thermal insulation to the test vessel. This type of boiling tests provided the baseline case for heat removal performance achieved under ERVC conditions without any enhancement.

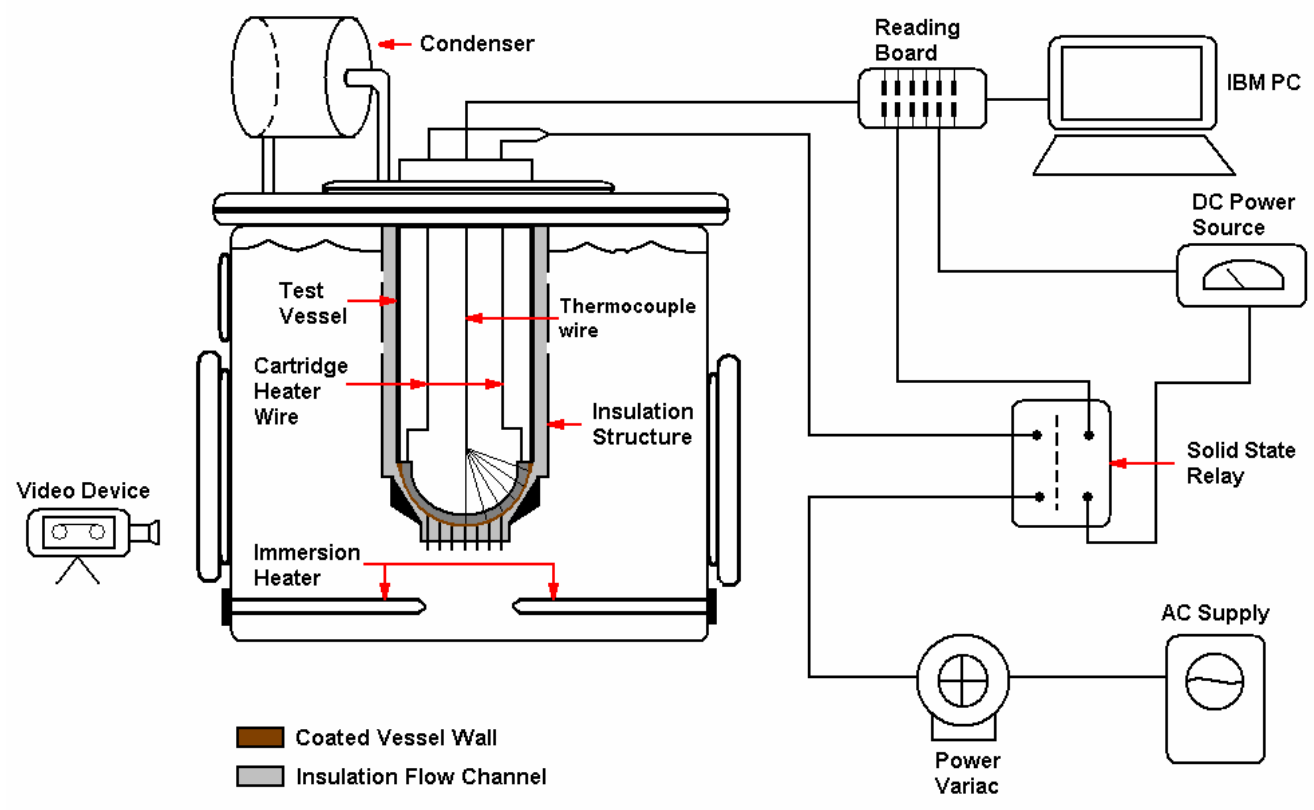

Figure 3. OVERALL SCHEMATIC DIAGRAM OF THE SBLB TEST FACILITY 


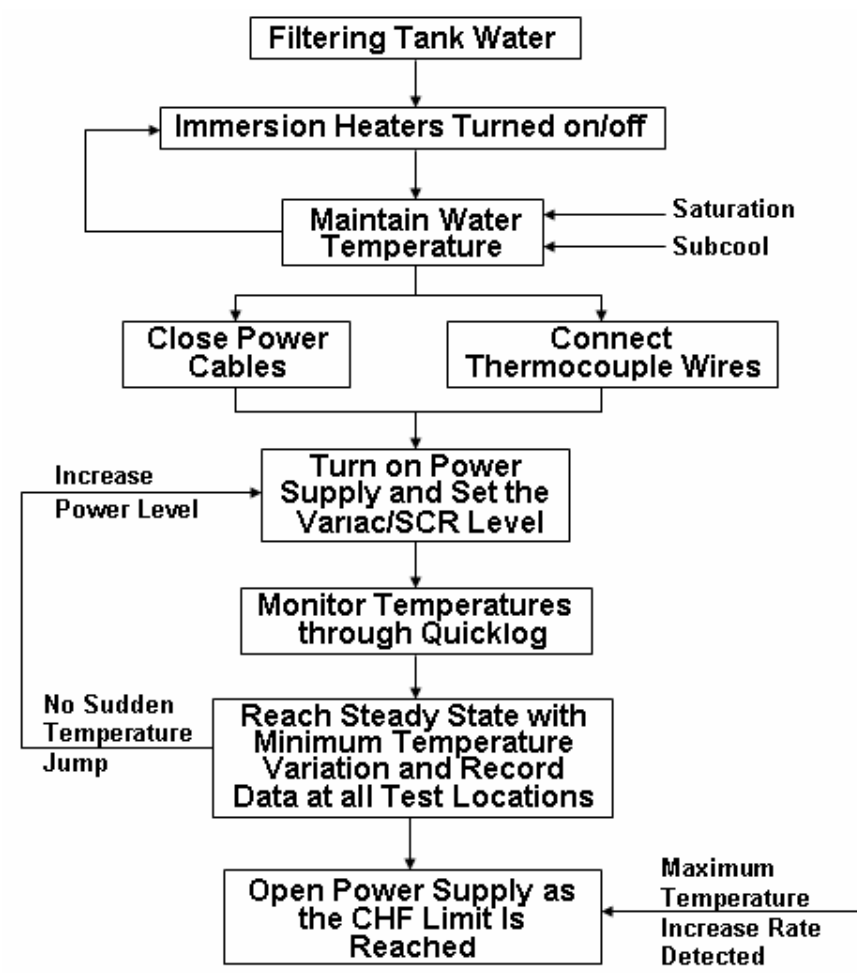

Figure 4. STEADY STATE BOILING TEST PROCEDURE

2. Coated Vessel Without Thermal Insulation: For this type of boiling tests, aluminum micro-porous surface coating was first applied on the outer surface of the vessel wall. An optimized coating mixture and a suitable application method were used to ensure a coating product with desired uniform thickness and pore distribution. By comparing the results obtained for this type of boiling tests to the baseline case, the separate effect of coating was determined.

3. Plain Vessel With Enhanced Thermal Insulation: For this type of boiling tests, the outer surface of vessel wall was first treated as done in the baseline case. Then, the enhanced thermal insulation structure was installed on the test vessel. By comparing the results obtained for this type of boiling tests to the baseline case, the separate effect of enhanced thermal insulation structure was determined.

4. Coated Vessel With Enhanced Thermal Insulation: This type of boiling tests investigated the integral effect of using the two ERVC enhancement methods simultaneously: using aluminum micro-porous surface coating to promote local boiling heat transfer while using enhanced thermal insulation to improve the global steam venting process. By comparing the results obtained for this type of boiling tests to the above three sets of results, the integral effect of the two ERVC enhancement methods was determined.

\section{RESULTS AND DISCUSSION}

\section{Nucleate Boiling Heat Transfer}

Figure 5 shows the nucleate boiling data measured for the baseline case (i.e. plain vessel without surface coating or thermal insulation structure) at five angular locations along the vessel surface starting from the vessel bottom center where $\theta=0^{\circ}$. In this figure, the local boiling heat fluxes are plotted against the local wall superheat. It can be seen that the nucleate boiling rate tended to increase as the angular location moves upward from the bottom center toward the equator of the test vessel. The CHF limits, which correspond to the maximum location of the nucleate boiling curves, also increased with the angular position.

Nucleate boiling correlations were developed from the boiling data using semi-log scale polynomial fittings. The general form of the correlations is

$$
q_{\text {wall }}^{\prime \prime}=a(\ln \Delta T)^{3}+b(\ln \Delta T)^{2}+c(\ln \Delta T)+d\left(\mathrm{MW} / \mathrm{m}^{2}\right)
$$

where $\Delta \mathrm{T}$ is the wall superheat in degree Celsius.

$$
\begin{aligned}
& \theta=0^{\circ}, 6^{\circ} \mathrm{C}<\Delta \mathrm{T}<47.4^{\circ} \mathrm{C} \text { : } \\
& q_{N B}^{\prime \prime}=-0.057(\ln \Delta T)^{3}+0.522(\ln \Delta T)^{2}-1.341(\ln \Delta T)+1.124 \\
& \theta=14^{\circ}, 8^{\circ} \mathrm{C}<\Delta \mathrm{T}<52.7^{\circ} \mathrm{C} \text { : } \\
& q_{N B}^{\prime \prime}=-0.0441(\ln \Delta T)^{3}+0.408(\ln \Delta T)^{2}-1.011(\ln \Delta T)+0.836 \\
& \theta=28^{\circ}, 9^{\circ} \mathrm{C}<\Delta \mathrm{T}<64.8^{\circ} \mathrm{C} \text { : } \\
& q_{N B}^{\prime \prime}=-0.0153(\ln \Delta T)^{3}+0.181(\ln \Delta T)^{2}-0.438(\ln \Delta T)+0.353 \\
& \theta=42^{\circ}, 7^{\circ} \mathrm{C}<\Delta \mathrm{T}<63^{\circ} \mathrm{C} \text { : } \\
& q_{N B}^{\prime \prime}=-0.0488(\ln \Delta T)^{3}+0.569(\ln \Delta T)^{2}-1.738(\ln \Delta T)+1.705 \\
& \theta=56^{\circ}, 7^{\circ} \mathrm{C}<\Delta \mathrm{T}<59.1^{\circ} \mathrm{C} \text { : } \\
& q_{N B}^{\prime \prime}=-0.215(\ln \Delta T)^{3}+2.01(\ln \Delta T)^{2}-5.673(\ln \Delta T)+5.134
\end{aligned}
$$

Figure 6 presents the nucleate boiling data for a coated vessel without an insulation structure. By comparing the nucleate boiling curves obtained at different angular locations, it can be seen that for a coated vessel, the nucleate boiling rates and CHF limits were considerably higher than those for the baseline case. Moreover, contrary to what was observed for the baseline case, the nucleate boiling rates and CHF limits for a coated vessel did not increase monotonically with the angular location as shown by the data at $\theta=0^{\circ}, 14^{\circ}$ and $28^{\circ}$. This nonmonotonic behavior was a result of the capillary action of the coating and the convergent effect of the bottom center. Water was drawn into the coating by the capillary action and then supplied toward the bottom center from all directions. These promoted nucleate boiling heat transfer and helped prevent dryout at the bottom center, thereby increasing the local boiling rate and the local CHF limit. 


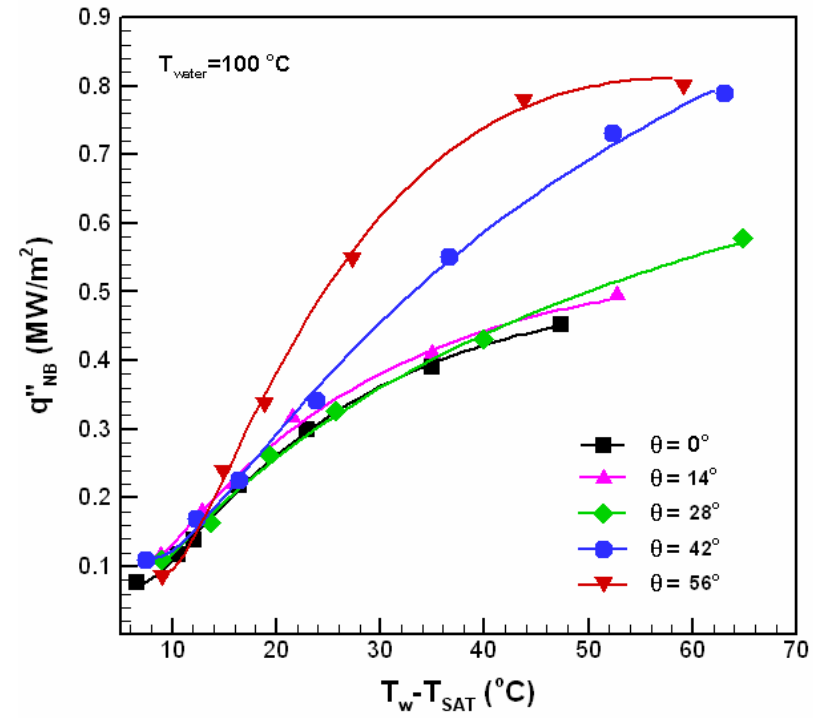

FIGURE 5. NUCLEATE BOILING DATAAND CORRELATIONS FOR A PLAIN VESSEL

The following equations summarize the nucleate boiling correlations for a coated vessel without an insulation structure:

$$
\begin{aligned}
& \theta=0^{\circ}, 13^{\circ} \mathrm{C}<\Delta \mathrm{T}<135.3^{\circ} \mathrm{C}: \\
& \quad q_{N B}^{\prime \prime}=-0.0796(\ln \Delta T)^{3}+0.87(\ln \Delta T)^{2}-2.772(\ln \Delta T)+2.92
\end{aligned}
$$

$\theta=14^{\circ}, 7.3^{\circ} \mathrm{C}<\Delta \mathrm{T}<92.3^{\circ} \mathrm{C}$ :

$$
q_{N B}^{\prime \prime}=-0.095(\ln \Delta T)^{3}+0.881(\ln \Delta T)^{2}-2.318(\ln \Delta T)+1.999
$$

$\theta=28^{\circ}, 13^{\circ} \mathrm{C}<\Delta \mathrm{T}<158.4^{\circ} \mathrm{C}$ :

$$
q_{N B}^{\prime \prime}=-0.0122(\ln \Delta T)^{3}+0.129(\ln \Delta T)^{2}-0.188(\ln \Delta T)+0.051
$$

$\theta=42^{\circ}, 10^{\circ} \mathrm{C}<\Delta \mathrm{T}<97^{\circ} \mathrm{C}$ :

$$
q_{N B}^{\prime \prime}=-0.009(\ln \Delta T)^{3}+0.21(\ln \Delta T)^{2}-0.674(\ln \Delta T)+0.718
$$

$\theta=56^{\circ}, 7^{\circ} \mathrm{C}<\Delta \mathrm{T}<126^{\circ} \mathrm{C}$ :

$$
q_{N B}^{\prime \prime}=-0.0345(\ln \Delta T)^{3}+0.345(\ln \Delta T)^{2}-0.687(\ln \Delta T)+0.651
$$

Figure 7 shows the nucleate boiling data measured for a plain vessel surrounded by an enhanced insulation structure. Comparing to the nucleate boiling curves shown in Fig. 5 and 6 for vessels without an insulation structure, the nucleate boiling rate in Fig. 7 increased at a higher rate with the wall superheats because of the influence of the enhanced insulation structure. Owing to the variation of the cross-sectional area of the flow channel formed between the vessel wall and the insulation structure, the nucleate boiling curves did not exhibit any monotonic trend with respect to the angular location.

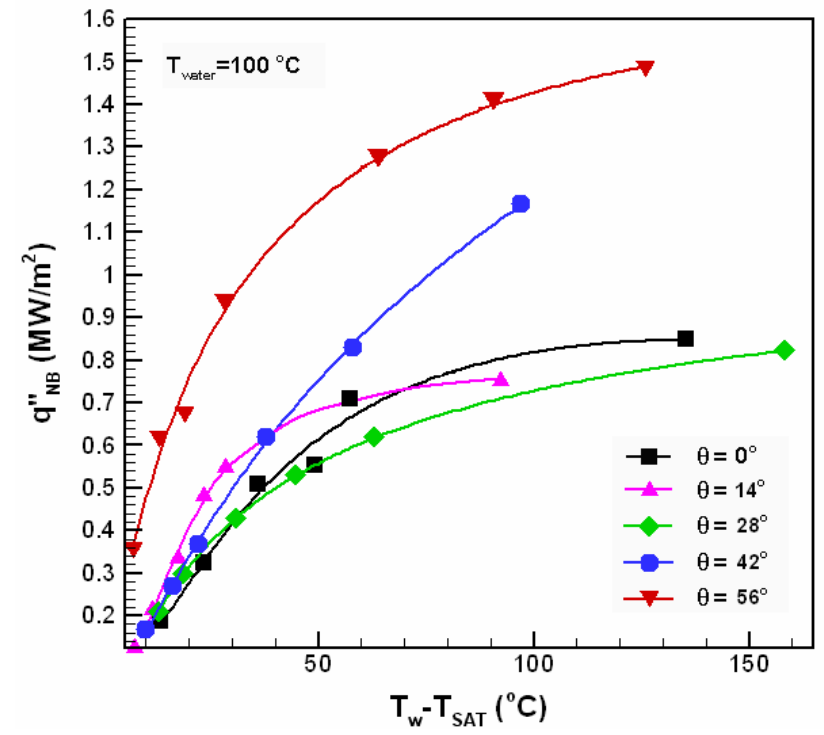

FIGURE 6. NUCLEATE BOILING DATAAND CORRELATIONS FOR A COATED VESSEL

The following equations summarize the nucleate boiling correlations for a plain vessel with an enhanced insulation structure:

$$
\begin{aligned}
& \theta=0^{\circ}, 13^{\circ} \mathrm{C}<\Delta \mathrm{T}<63.2^{\circ} \mathrm{C}: \\
& q_{N B}^{\prime \prime}=0.267(\ln \Delta T)^{3}-2.229(\ln \Delta T)^{2}+6.54(\ln \Delta T)-6.422
\end{aligned}
$$

$\theta=18^{\circ}, 21^{\circ} \mathrm{C}<\Delta \mathrm{T}<67^{\circ} \mathrm{C}$ :

$$
q_{N B}^{\prime \prime}=-0.0109(\ln \Delta T)^{3}+0.588(\ln \Delta T)^{2}-2.868(\ln \Delta T)+3.942
$$

$\theta=45^{\circ}, 15^{\circ} \mathrm{C}<\Delta \mathrm{T}<54^{\circ} \mathrm{C}$

$$
q_{N B}^{\prime \prime}=-0.284(\ln \Delta T)^{3}+3.177(\ln \Delta T)^{2}-10.78(\ln \Delta T)+11.86
$$

$\theta=60^{\circ}, 17^{\circ} \mathrm{C}<\Delta \mathrm{T}<58^{\circ} \mathrm{C}$ :

$$
q_{N B}^{\prime \prime}=-0.251(\ln \Delta T)^{3}+2.721(\ln \Delta T)^{2}-8.677(\ln \Delta T)+8.82
$$

$\theta=75^{\circ}, 22^{\circ} \mathrm{C}<\Delta \mathrm{T}<64^{\circ} \mathrm{C}$ :

$$
q_{N B}^{\prime \prime}=0.83(\ln \Delta T)^{3}-7.958(\ln \Delta T)^{2}+26.30(\ln \Delta T)-29.48
$$

Figure 8 presents the nucleate boiling data measured for a coated vessel surrounded by an enhanced insulation structure, showing the integral effect of the two ERVC enhancement methods. Although the vessel had a micro-porous surface coating, the boiling curves were more similar to those shown in Fig. 7 than to those in Fig. 5 and 6. Evidently, the enhancement effect of the insulation structure dominated the boiling heat transfer performance of the test vessel. Owing to the variation of the cross-sectional flow area, the nucleate boiling curves did not exhibit any monotonic trend. 


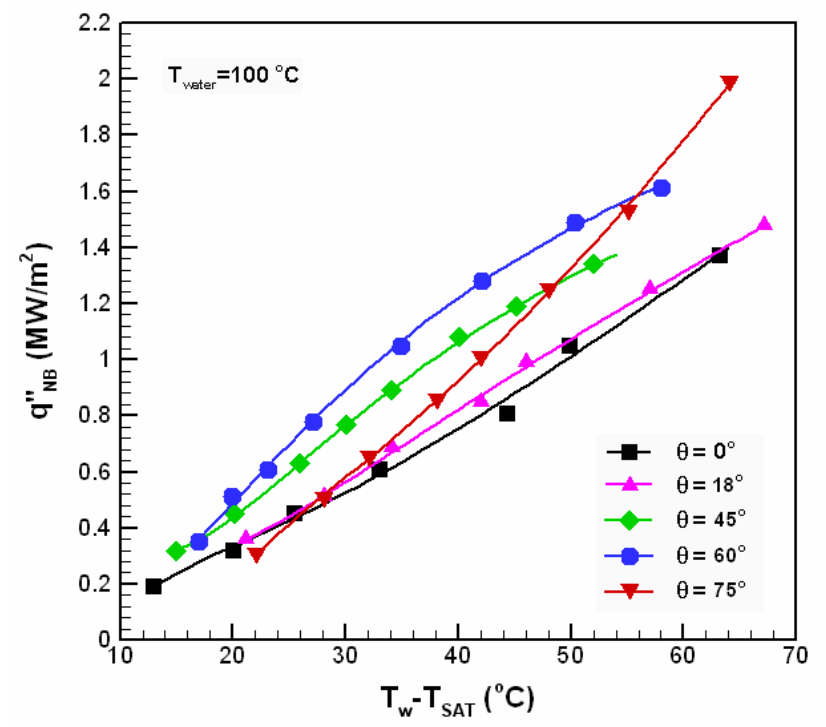

\section{FIGURE 7. NUCLEATE BOILING DATAAND CORRELATIONS FOR A PLAIN VESSEL WITH ENHANCED INSULATION STRUCTURE}

The following equations summarize the nucleate boiling correlations for a coated vessel with an enhanced insulation structure:

$$
\begin{aligned}
\theta= & 0^{\circ}, 16^{\circ} \mathrm{C}<\Delta \mathrm{T}<61^{\circ} \mathrm{C}: \\
& q_{N B}^{\prime \prime}=0.163(\ln \Delta T)^{3}-1.17(\ln \Delta T)^{2}+3.072(\ln \Delta T)-2.677 \\
\theta= & 18^{\circ}, 12^{\circ} \mathrm{C}<\Delta \mathrm{T}<65^{\circ} \mathrm{C}: \\
& q_{N B}^{\prime \prime}=-0.0154(\ln \Delta T)^{3}+0.472(\ln \Delta T)^{2}-1.835(\ln \Delta T)+2.163
\end{aligned}
$$

$\theta=45^{\circ}, 10^{\circ} \mathrm{C}<\Delta \mathrm{T}<45^{\circ} \mathrm{C}$ :

$$
q_{N B}^{\prime \prime}=0.311(\ln \Delta T)^{3}-2.345(\ln \Delta T)^{2}+6.205(\ln \Delta T)-5.309
$$

$\theta=60^{\circ}, 12^{\circ} \mathrm{C}<\Delta \mathrm{T}<52^{\circ} \mathrm{C}$ :

$$
q_{N B}^{\prime \prime}=-0.2(\ln \Delta T)^{3}+2.209(\ln \Delta T)^{2}-6.756(\ln \Delta T)+6.665
$$

$$
\begin{aligned}
& \theta=75^{\circ}, 16^{\circ} \mathrm{C}<\Delta \mathrm{T}<53^{\circ} \mathrm{C}: \\
& q_{N B}^{\prime \prime}=-0.866(\ln \Delta T)^{3}+9.111(\ln \Delta T)^{2}-30.28(\ln \Delta T)+32.86
\end{aligned}
$$

\section{Spatial Variation of CHF}

Figure 9 shows the spatial variation of the local CHF limits along the outer vessel wall for the four different types of steadystate boiling experiments. By comparing the $\mathrm{CHF}$ variations obtained for the four different types, the separate and integral effects of the two ERVC enhancement methods could be studied. The CHF limits for type 2, 3 and 4 experiments were consistently higher than those for the baseline case at all angular locations. For type 4 experiments, where both ERVC enhancement methods were used, the highest CHF limits were reached. However, the CHF variation for type 4 was more similar to that for type 3 than to the CHF variation for type 2 because the enhancement effect of the insulation structure dominated the boiling performance, as discussed in previous section.

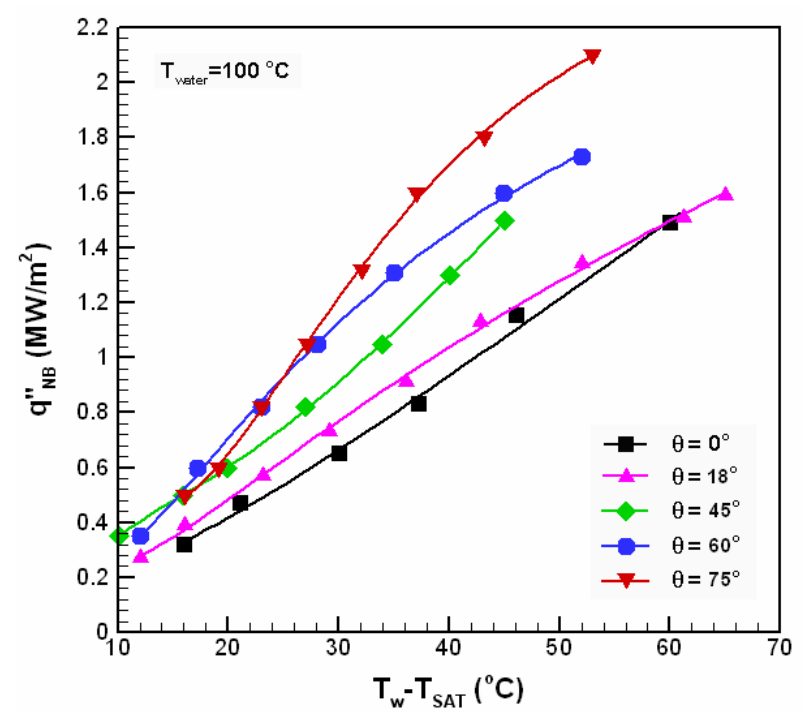

FIGURE 8. NUCLEATE BOILING DATAAND CORRELATIONS FOR A COATED VESSEL WITH ENHANCED INSULATION STRUCTURE

For the baseline case, the local CHF along the angular location had the following profile:

$$
\left(q_{C H F}^{\prime \prime}\right)_{O}=\left(1+0.036 \Delta T_{\text {sub }}\right)\left(0.434+0.347 \theta+0.0604 \theta^{2}\right)
$$

where $\theta$, measuring from the bottom center of the vessel, is in radian and $\Delta T_{s u b}$ accounts for the subcooling effect on the local CHF limit.

For type 2 experiments, the local CHF along the angular location had the following profile:

$$
\left(q_{C H F}^{\prime \prime}\right)_{C}=\left(1+0.036 \Delta T_{\text {sub }}\right)\left(0.853-1.083 \theta+2.63 \theta^{2}-0.94 \theta^{3}\right)
$$

For type 3 experiments, the local CHF had different profiles for three separate regions within $0<\theta<\pi / 2$ test range due to the variation of the cross-sectional flow area formed between the vessel and the thermal insulation structure:

In the bottom center region of the channel where $0<\theta<0.314$, the experimental results give rise to the following CHF correlation:

$$
\left(q_{C H F}^{\prime \prime}\right)_{E I}=(1.37+0.35 \theta)
$$


In the convergent region covering the upper exit of the inlet section up to the shear key location where $0.314<\theta<0.785$, the experimental results give rise to the following correlation:

$$
\left(q_{C H F}^{\prime \prime}\right)_{E I}=(1.573-0.295 \theta)\left[1+0.0925(\theta-0.314)^{1 / 3} \Delta T_{\text {sub }}\right]
$$

In the divergent region covering the upper part of the channel beyond the shear key location where $0.785<\theta<1.571$, the experimental results give rise to the following correlation:

$$
\left(q_{C H F}^{\prime \prime}\right)_{E I}=\left(1.19-0.439 \theta+0.803 \theta^{2}\right)\left[1+0.0746(1-0.573(\theta-0.785)) \Delta T_{s u b}\right]
$$

For type 4 experiments, the local CHF had a similar behavior as that for type 3 . In the bottom center region of the channel where $0<\theta<0.314$, the experimental results give rise to the following CHF correlation:

$$
\left(q_{C H F}^{\prime \prime}\right)_{C+E I}=(1.49+0.318 \theta)\left(\mathrm{MW} / \mathrm{m}^{2}\right)
$$

In the convergent region covering the upper exit of the inlet section up to the shear key location where $0.314<\theta<0.785$, the experimental results give rise to the following correlation:

$$
\left(q_{C H F}^{\prime \prime}\right)_{C+E I}=(1.65-0.191 \theta)\left[1+0.0925(\theta-0.314)^{1 / 3} \Delta T_{\text {sub }}\right]
$$

In the divergent region covering the upper part of the channel beyond the shear key location where $0.785<\theta<1.571$, the experimental results give rise to the following correlation:

$$
\left(q_{C H F}^{\prime \prime}\right)_{C+E I}=\left(1.65-0.993 \theta+1.021 \theta^{2}\right)\left[1+0.0746(1-0.573(\theta-0.785)) \Delta T_{\text {sub }}\right]
$$

\section{CHF Enhancement Factors}

To quantitatively evaluate the separate and integral effects of the two ERVC enhancement methods, CHF enhancement factors were determined by comparing the experimental results for type 2, 3 and 4 experiments to the baseline case.

The enhancement factor $\left(F_{C}\right)_{\mathrm{o}}$ was correlated by curve fitting the CHF ratio obtained in type 2 experiments (i.e., equation 23) and baseline case experiments (i.e., equation 22), as follows:

for $0<\theta<0.38$ :

$\left(F_{C}\right)_{O}=\frac{\left(q_{C H F}^{\prime \prime}\right)_{C}}{\left(q_{C H F}^{\prime \prime}\right)_{O}}=\left(1.88-2.35 \theta+2.37 \theta^{2}\right)$

for $0.38<\theta<1.57$ :

$$
\left(F_{C}\right)_{O}=\frac{\left(q_{C H F}^{\prime \prime}\right)_{C}}{\left(q_{C H F}^{\prime \prime}\right)_{O}}=\left(1.73-2.14 \theta+3.63 \theta^{2}-1.45 \theta^{3}\right)
$$

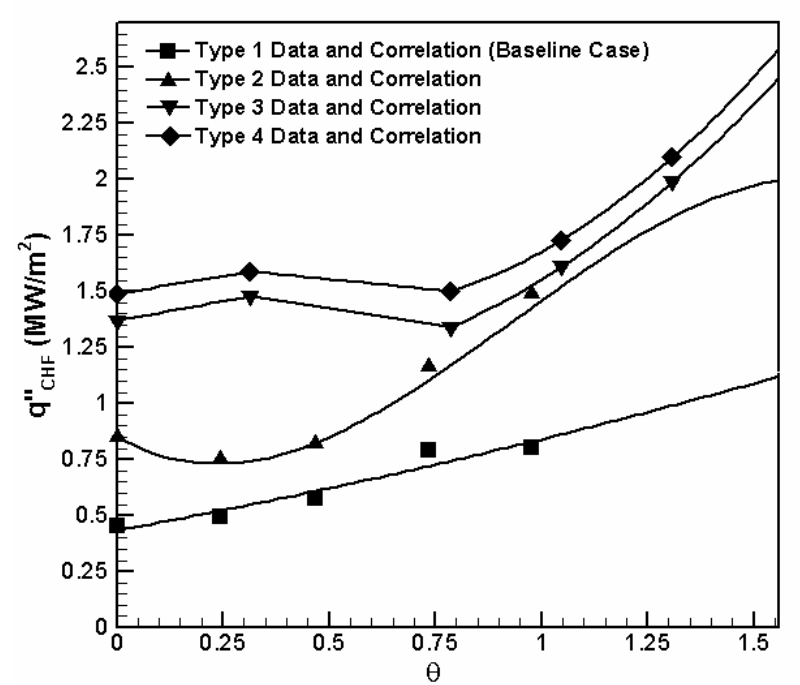

\section{FIGURE 9. SPATIAL VARIATION OF THE LOCAL CHF AND CORRELATION CURVES}

The enhancement factor $F_{E I}$ was correlated by comparing the type 3 test data (i.e., equation 24) to the baseline case data given by equation (22):

$$
\begin{array}{ll}
F_{E I}=\frac{\left(q_{C H F}^{\prime \prime}\right)_{E I}}{\left(q_{C H F}^{\prime \prime}\right)_{O}}=F_{\text {sub }}(3.024-1.042 \theta) & \text { for } 0<\theta<0.314 \\
F_{E I}=\frac{\left(q_{C H F}^{\prime \prime}\right)_{E I}}{\left(q_{C H F}^{\prime \prime}\right)_{O}}=F_{\text {sub }}(3.293-1.898 \theta) & \text { for } 0.314<\theta<0.785 \\
F_{E I}=\frac{\left(q_{C H F}^{\prime \prime}\right)_{E I}}{\left(q_{C H F}^{\prime \prime}\right)_{O}}=F_{\text {sub }}(1.547+0.325 \theta) & \text { for } 0.785<\theta<1.571
\end{array}
$$

The subcooling effect in equations (31a) to (31c) is given in the following equations for corresponding angular regions:

$$
F_{\text {sub }}=\left\{\begin{array}{r}
\left(1+0.036 \Delta T_{\text {sub }}\right)^{-1} \text { for } 0<\theta<0.314 \\
{\left[1+0.0925(\theta-0.314)^{1 / 3} \Delta T_{\text {sub }}\right]\left(1+0.036 \Delta T_{\text {sub }}\right)^{-1}} \\
\text { for } 0.314<\theta<0.785 \\
{\left[1+0.0746(1-0.573(\theta-0.785)) \Delta T_{\text {sub }}\right]\left(1+0.036 \Delta T_{\text {sub }}\right)^{-1}} \\
\text { for } 0.785<\theta<1.571
\end{array}\right.
$$

The integral effect of an enhanced insulation structure and vessel coating can be obtained by comparing the experimental results given by Eq. (26)-(28) to the results given by Eq. (22). The resulting enhancement factor $F_{C+E I}$ can be correlated as follows,

$F_{C+E I}=\frac{\left(q_{C H F}^{\prime \prime}\right)_{C+E I}}{\left(q_{C H F}^{\prime \prime}\right)_{O}}=F_{\text {sub }}(3.289-1.154 \theta)$ for $0<\theta<0.314$ 


$$
\begin{aligned}
& F_{C+E I}=\frac{\left(q_{C H F}^{\prime \prime}\right)_{C+E I}}{\left(q_{C H F}^{\prime \prime}\right)_{O}}=F_{\text {sub }}(3.528-1.915 \theta) \text { for } 0.314<\theta<0.785(33 \mathrm{~b}) \\
& F_{C+E I}=\frac{\left(q_{C H F}^{\prime \prime}\right)_{C+E I}}{\left(q_{C H F}^{\prime \prime}\right)_{O}}=F_{\text {sub }}\left(2.83-1.761 \theta+0.936 \theta^{2}\right)
\end{aligned}
$$$$
\text { for } 0.785<\theta<1.571
$$

The subcooling effect $F_{\text {sub }}$ is given by equation (32).

Figure 10 summarizes the distribution of the CHF enhancement factors, $\left(F_{C}\right)_{0}, F_{E I}$ and $F_{C+E I}$. It can be seen that for $0<\theta<\pi / 4$, the enhanced insulation structure could improve boiling heat transfer and CHF limits remarkably. The similarity between $F_{E I}$ and $F_{C+E I}$ can be attribute to the fact that the insulation structure had a dominant effect over the vessel coating. In Fig. 10, the dashed line, $\left(F_{C}\right)_{0} * F_{E I}$, provides the idealized enhancement that could have been achieved if there were no interference between the two ERVC enhancement methods. However, the integral factor, $F_{C+E I}$, appears much less than the idealized value $\left(F_{C}\right)_{0}{ }^{*} F_{E I}$ because of possible competing mechanisms between the two enhancement methods.

\section{CONCLUSIONS}

A series of steady state boiling experiments were performed for four different ERVC configurations to investigate the efficacy of two distinct ERVC enhancement methods. Based on the steady state boiling data, nucleate boiling and CHF correlations were developed by data fitting. A set of CHF enhancement factors were also established to quantitatively characterize the enhancement offered by the two methods. Based on the results obtained in this study, the following conclusions can be made:

1. Both ERVC enhancement methods appeared to be quite effective. At a given angular location, the nucleate boiling heat transfer and the local CHF could be increased considerably by using either vessel coating or an enhanced insulation structure.

2. Depending on the angular location, the local CHF limit could be enhanced by 1.4 to 2.5 times using vessel coating alone whereas it could be enhanced by 1.8 to 3.0 times using an enhanced insulation structure alone.

3. Unlike the baseline case for which the local CHF limit increased monotonically with the angular location, the local CHF limit for the case with either vessel coating or insulation structure exhibited a non-monotonic behavior.

4. For a coated vessel without insulation, the CHF had a local peak at the bottom center, as a result of the capillary action of the micro-porous coating and the convergent effect of the bottom center.

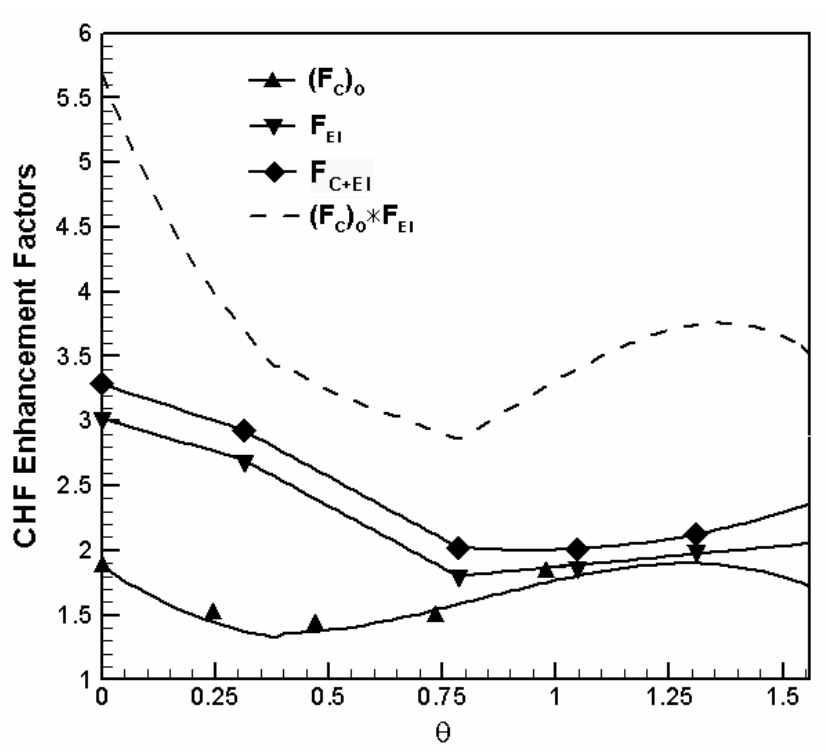

\section{FIGURE 10. DISTRIBUTION OF THE CHF ENHANCEMENT FACTORS}

5. For the case with an enhanced insulation structure but without coating, the non-monotonic behavior of the local CHF limit was a direct consequence of the variation of the cross-sectional flow area formed between the vessel and the insulation structure, which led to different steam venting rates through the flow channel.

6. The local CHF for the case using both vessel coating and insulation structure exhibited a similar behavior (i.e., similar angular variation) as the local CHF for the case with insulation structure but without vessel coating. Evidently, the insulation structure had a dominant effect over the vessel coating.

7. The combined CHF enhancement factor which represents the integral effect of the two ERVC enhancement methods, appeared much less than the product of the two separate enhancement factors due to vessel coating alone and enhanced insulation alone. This indicates that there were competing mechanisms (i.e., interference) between the two enhancement methods.

\section{ACKNOWLEDGMENTS}

This work was performed under DOE contract number DEAC07-99ID13727. The authors are grateful for the financial support by the U.S. Department of Energy and the Korean Ministry of Science and Technology as part of the K-INERI program.

\section{REFERENCES}

Chang, J. Y. and You, S. M., 1996, Heater Orientation Effects on Pool Boiling of Micro-Porous-Enhanced Surfaces in 
Saturated FC-72, ASME J. Heat Transfer, Vol. 118, No. 4, pp. 937-943.

Chang, J. Y. and You, S. M., 1997, Boiling Heat Transfer Phenomena From Micro-porous and Porous Surfaces in Saturated FC-72, Int. J. Heat Mass Transfer., Vol. 40, No. 18, pp. 4437-4447.

Cheung, F. B., Haddad, K. and Liu, Y. C., 1997, Critical Heat Flux (CHF) Phenomena on a Downward Facing Curved Surface, NUREG/CR-6507, U.S. Nuclear Regulatory Commission, Washington, D.C.

Cheung, F. B. and Liu, Y. C., 1998, Critical Heat Flux (CHF) Phenomenon on a Downward Facing Curved Surface: Effects of Thermal Insulation, NUREG/CR-5534, U.S. Nuclear Regulatory Commission, Washington, D.C.

Cheung, F. B., Yang, J. and Dizon, M. B., 2003, On the Enhancement of External Reactor Vessel Cooling of HighPower Reactors, The $10^{\text {th }}$ International Topical Meeting on Nuclear Reactor Thermal Hydraulics (NURETH-10), Paper G00403.

Czikk, A. M., O’Neill, P. S., and Gottzmann, C. F., 1981 Nucleate Boiling from Porous Metal Films: Effect of Primary Variables, ASME Symp. Vol. HTD-Vol.-18, Advances in Enhanced Heat Transfer.
Dizon, M. B., Yang, J. and Cheung, F. B., 2004, Effects of surface coating on the critical heat flux for pool boiling from a downward facing surface, Journal of Enhanced Heat Transfer, 11(2), 133150.

Haddad, K. H., 1996, An experimental and theoretical study of two-phase boundary layer flow on the outside of curved downward-facing surfaces, Ph.D. Dissertation, Pennsylvania State University, University Park.

Liter, S. G. and Kaviany, M., 2001, Pool-boiling CHF enhancement by modulated porous-layer coating: theory and experiment, Int. J. Heat Mass Transfer, 44 , pp. 4287-4311.

Liu, Y. C., 1999, Buoyancy-driven co-current two-phase flow in a hemispherical annular channel with natural convection boiling on the downward facing side, Ph.D. Dissertation, Pennsylvania State University, University Park.

Of入onnor, J. P. and You, S. M., 1995, A Painting Technique to Enhance Pool Boiling Heat Transfer in FC-72, ASME J. Heat Transfer, Vol. 117, No. 2, pp. 387-393.

Yang, J. and Cheung, F. B., 2005, A Hydrodynamic CHF Model for Downward Facing Boiling on a Coated Vessel", Int. J. Heat \& Fluid Flow, in press. 